\title{
The Concentration of 25-Hydroxy Vitamin D in Chronic Liver Disease and Its Correlation with Severity
}

\author{
Farid Ahmed ${ }^{1 *}$, Pinaki Paul ${ }^{2}$, Anwarul Kabi ${ }^{3}$ and Rashedul Hasan ${ }^{4}$ \\ ${ }^{1}$ Assistant Professor, Department of Gastroenterology, Sheikh Russel National Gastroliver Institute \& Hospital, Mohakhali, Dhaka, Bangladesh \\ ${ }^{2}$ Assistant Professor, Department of Gastroenterology, Shahid Syed Nazrul Islam Medical College, Kishoreganj, Bangladesh \\ ${ }^{3}$ Professor, Department of gastroenterology, BSMMU, Dhaka, Bangladesh \\ ${ }^{4}$ Assistant professor, Department of Gastroenterology, Sheikh Russel National Gastroliver Institute \& Hospital, Mohakhali, Dhaka, Bangladesh \\ Corresponding Author: Farid Ahmed, Assistant Professor, Department of Gastroenterology, Sheikh Russel National Gastroliver Institute \& \\ Hospital, Mohakhali, Dhaka, Bangladesh
}

Received date: January 26, 2021; Accepted date: March 19, 2021; Published date: March 22,2021

Citation: Ahmed F., Pinaki Paul, Kabi A. and Hasan R. (2021) The Concentration of 25-Hydroxy Vitamin D in Chronic Liver Disease and Its Correlation with Severity J. Gastroenterology Pancreatology and Hepatobilary Disorders 5(1) DOI:10.31579/2641-5194/018

Copyright: () 2021, Farid Ahmed,This is an open access article distributed under the Creative Commons Attribution License, which permits unrestricted use, distribution, and reproduction in any medium, provided the original work is properly cited.

\begin{abstract}
Background: Chronic liver disease (CLD is a common disease all over the world and the major cliological factors for the causation of disease are HBV and HCV in this country and Alcoholic liver disease in the western world. With the availability of the modern treatment, the life expectancy is increased now a days. But the long term complications are now evident. One of the complications is hepatic osteodystrophy which is associated with deficiency of vitamin D. Vitamin D undergoes hepatic 25-hydroxylation, but as the hepatic parenchyma is jeopardized so the metabolic activation of this vitamin is impaired. Vitamin D deficiency is highly prevalent in CLD patients and vitamin D level is inversely related to the severity of the disease.
\end{abstract}

Objective: To assess the concentration of 25-hydroxy vitamin D in chronic liver disease patient in different etiology and to study the relationship of level of $25(\mathrm{OH}) \mathrm{D}$ in different stages of the disease according to Child-Pugh classification.

Methods: This cross sectional study was carried out in the Department of Gastroenterology, Bangabandhu Sheikh Mujib Medical University, Dhaka during the period of April 2015 to March 2016. Patient attending the Gastroenterology Department who fulfill the inclusion criteria with cirrhosis of liver were initially be enrolled for the study. Their clinical history, examination and initial investigation report were noted in the standard data sheet. After explaining the study objective, informed consent was taken. The diagnosis of liver cirrhosis was made by combination of clinical features, blood profile and transabdominal ultrasound. Endoscopy of the upper GIT was done to see the presence of oesophageal or gastric varices which is a sign of increase portal pressure. Transabdominal ultrasound demonstrated a shrunken liver with increase echogenicity, with or without splenomegally and presence or absence of ascites. Stages of liver disease were assessed by Child-Pugh scoring system. Level of $25(\mathrm{OH}) \mathrm{D}$ was measured from blood with the permission of the Department of Bio-chemistry. Data was collected using a structered data sheet.

Results: Out of 85 patients, male were $61(71.8 \%)$ and female were $24(28.2 \%)$. Mean age was $53.0 \pm 10.7$ years within tin- range of 25-70 years. More than $90.0 \%$ patient* had abates and anorexia. Eighty percent patients had weight loss and $71.8 \%$ patients had Jaundice. More than $40.0 \%$ patients had abdominal pain and melaena. Sixty (77.9\%) patients had history of blood transfusion and $73(94.8 \%)$ patients had previous hospitalization, Most of the patients had anaemia (97.6\%) and Splenomegaly (92.9\%). More than 50.0\% patients had jaundice $(61.2 \%)$, Leukonychia (61.2\%) and hone pain (52.9\%). Mean s, vitamin 25(OH) D was $16.29 \pm 7.96$ in $69 \mathrm{HBV}$ patients and $20.14 \pm 9.76$ in $16 \mathrm{HCV}$ patients. In this study, 28.2\% patients were in child Pugh A, 36.4\% in child Pugh B and 32.9\% in child Pugh C stages. Mean s. vitamin 25(OH) D were $27.12 \pm 6.11,15.97 \pm 5.40$ and $9.57 \pm$ J.I5 in Child-pugh A, Child-pugh B and Child-pugh C stages respectively. Mean s. vitamin $25(\mathrm{OH})$ D was gradually decreased as the changes of stage from lower to higher. Conclusion: Vitamin D deficiency is highly prevalent in patients with CLD and inversely correlated with disease severity. In the case of chronic liver diseases, vitamin D seems to modulate the innate and adaptive immune system, which explains the association. In fact, clinical studies suggest that these parameters may improve with vitamin D supplementation. So, monitoring of S. $25(\mathrm{OH}) \mathrm{D}$ is reasonable in CLD patient.

Keywords: avitaminosis. Parathyroid hormone; p ortal hypertension; gastric varices; child-pugh A; child-pugh B And child-pugh $\mathrm{C}$ 


\section{Introduction}

Cirrhosis may be defined us a phase of chronic liver disease or insult leads to the diffuse destruction of hepatic parenchymal cell by fibrosis and the formation of nodules, which results in disorganization of the liver's lobular and vascular architecture. In western countries, common causes are alcohol. Where as in developing countries, common CHUM'S arc chronic hepatitis $\mathrm{B}$ or $\mathrm{C}$ virus infection [1]. Cirrhosis may be compensated or decompensated when complicated by jaundice, ascites, and hepatic encephalopathy or raised prothrombin time. It is insidious. Initially asymptomatic later present Iliih over! Complication [2]. The final stage of chronic inflammation in the liver is cirrhosis. Liver cirrhosis gives rise to portal hypertension and complications such as bleeding esophageal varices, ascites and encephalopathy. Hepato-cellular failure results in hyperbilirubinemia, hypoalbuminemia and prolonged prothrombin time. Child's grade is used to assess hepato-cellular function in cirrhosis based on these factors [3]. Though the disease is progressive, indolent and having many complications, but with the development of modern treatment modalities of cirrhosis of liver life span is increased. With the effective treatment long term complications are now commonly encountered. Metabolic bone disease occuring in patients with cirrhosis, known as hepatic osteodystrophy, covers both osteomalacia and osteoporosis [4]. It is a common complication among individuals with long standing hepatic disease. Various studies were conducted in different countries in the world to assess the prevalence of vitamin D deficiency in cirrhosis patient. One study was conducted in the University of Tennessee Hepatology clinic. Where one hundred and eighteen cirrhosis patients with different aetiology were included and their 25-hydroxy vitamin D level were measured. Severity was graded as mild $(20-32 \mathrm{ng} / \mathrm{ml})$, moderate $(7-19 \mathrm{ng} / \mathrm{ml})$ or severe $(<7 \mathrm{ng} / \mathrm{ml})$, normal being $>32 \mathrm{ng} / \mathrm{ml}$ [5]. Of patients one hundred eighteen, one hundred and nine had some degree of vitamin $\mathrm{D}$ deficiency. The result showed vitamin $\mathrm{D}$ deficiency is universal (92\%) among patients with cirrhosis and at least one third of them suffered from severe vitamin D deficiency [6]. Miroliace el al. of Iran, works with CLD patient where $\mathrm{HBV}(\mathrm{n}=26)$, HCV $(\mathrm{n}=28), \mathrm{AIH}$ $(n=19)$, Cryptogenic $(n=17)$ with 40 healthy controls [9]. Among the study population CM) group 56\% male and Control group $60 \%$ male. The main outcome is significantly higher prevalence of vitamin $\mathrm{D}$ deficiency in cirrhotic versus non-cirrhotic patient ( $76 \%$ vs $17.9 \%, \mathrm{P}<0.001)$. ChildPugh class $\mathrm{H}$ and $\mathrm{C}$ had significantly lower vitamin D levels than class A $(\mathrm{P}<0.001)$. Rode et al of Australia works with 158 patient where cirrhosis $(n=65)$ and no cirrhosis $(n=93)$. They categorize the patients in Viral (60), NASH (23), Alcoholic (22), Autoimmune (12), Haemochromatosis (9), Wilson's (2) Cholestatic (5) and others (25) [8]. Among the study population, $52 \%$ male. And they found that $49 \%$ had deficiency and $15 \%$ had severe deficiency of $25(\mathrm{OM}) \mathrm{D}$. Their outcome also suggest that patient with cirrhosis were more likely to be deficient in $25(\mathrm{OH}) \mathrm{D}(75 \%$, $\mathrm{P}=0.028$ ). Other studies, such as Petta et al showed $73 \%$ and Bitetto et al showed level of vitamin D deficiency was $73 \%$ and $46.4 \%$ respectively [7]. Lange et al in 2012 also worked with 269 patient and found $74 \%$ of the cirrhotic patient with vitamin D deficiency. So, all the studies showed vitamin $\mathrm{D}$ deficiency with a significant $\mathrm{P}$ value. Osteoporosis is a multifactorial disease and the most common bone disease characterized by a reduced bone mass and increase in bone fracturability due to distortion of bone tissue microstructure. Osteoporosis in CLD mainly affects trabecular bone and has been characterized by low bone turnover with reduced osteoblast function and low serum osteocalcin levels [11]. There are several causes for the deficiency of vitamin D in chronic liver disease. The important potential mechanisms are reduced exogenous exposure, intestinal malabsorption, reduced endogenous production of vitamin DBP and albumin in the liver, impaired hepatic hydroxylation of vitamin $\mathrm{D}$ to $25(\mathrm{OH}) \mathrm{D}$ and increased catabolic removal of $25(\mathrm{OH}) \mathrm{D}$ [10]. Vitamin D is a fat soluble vitamin and helps in absorption of calcium from the renal tubule and intestine. In patients with chronic liver disease, the prevalence of vitamin D deficits is much higher and practically universal. Up to $93 \%$ of patients with chronic liver disease have insufficient vitamin D levels, and almost one-third of these show severe deficiency [6]. The- important potential mechanism that reduce the level of vitamin D is multifactorial and van among different liver pathologies. Vitamin D3, is primarily acquired endogenously through the photochemical conversion of 7-dehydrocholestrol to previtamin D3 in the skin. Previtamin D3 is then converted to vitamin D3 through thermic isomerization. Then it is transported to the liver and hound to vitamin Dbinding protein. On the other hand, vitamin D2, following ingestion incorporated micelles. Then it is further amalgamated into chylomicrons via enterocyte absorption and reach the liver from venous circulation for hydroxylation. After hydroxylation, it is converted to 25 - hydroxivitamin $\mathrm{D}(25(\mathrm{OH}) \mathrm{D})$ and secreted in the circulation again mostly bound to DBF. Further hydroxylation to 1,25 -dihydroxivitamin $\mathrm{D}$ in the kidney converts the vitamin into its active form [17]. The pathogenesis of osteoporosis in CLD is complex and poorly understood. Advanced liver disease and cirrhosis are associated with an increased prevalence of osteoporosis [12]. The way in which liver failure affects osteoblasts and contributes to the development of osteoporosis is unclear. Numerous growth factors, some of which affect osteoblast function, such as IGF-1 and TGF-p are synthesized by the liver. Toxic substances, such as aluminum and copper, which accumulate in liver failure might also affect bone metabolism. In hemochromatosis an increased iron burden might impair osteoplastic activity [11]. Vitamin D maintains the normal skeletal architecture. It has effects on the immune system as well as have anti fibrotic effect. It exerts its effect in liver diseases by activating and regulating adequate innate and adaptive immunity. Vitamin D increases innate immunity, stimulating the mechanism associated with the elimination of pathogen agent through the secretion of antibacterial proteins, such as cathelicidin and beta-defensin and favouring chemotaxis and macrophage phagocytosis. $25(\mathrm{OH}) \mathrm{D}$ is the only vitamin D metabolite that is used to determine whether a patient is vitamin D deficient, sufficient or intoxicated. 25(OIi) D is the major circulating form of vitamin $D$ that has a half-life of approximately 2-3 weeks [5]. 25(OH) D is a summation of both vitamin D intake and vitamin $\mathrm{D}$ that is produced from sun exposure the biologically active form of vitamin D is I, 25(OH) D3. But this is not the ideal measure for vitamin $\mathrm{D}$ status due to several reasons. The circulating half-life of $1,25(\mathrm{OH}) \mathrm{D}$ is only 4-6 hours and this is thousand fold less than 25(OH)D. Besides this, when a person become vitamin D deficient, calcium absorption from the intestine and renal tubule will be less. So, a vitamin D deficient patient may have normal or elevated levels of $1,25(\mathrm{OH}) \mathrm{D}$ due to increase level of PTH. This makes the assay useless as a measure of vitamin D status. The only way to determine whether a person is vitamin $\mathrm{D}$ deficient or sufficient is to measure their circulating level of $25(\mathrm{OH}) \mathrm{D}$. There are a variety of assays used to measure $25(\mathrm{OH}) \mathrm{D}$. The radioimmunoassay and competitive protein binding assays for $25(\mathrm{OH}) \mathrm{D}$ are useful in delecting vitamin D deficiency and sufficiency. Vitamin D deficiency was defined as serum $25(\mathrm{OH})$ D levels less than $20 \mathrm{ng} / \mathrm{ml}(50 \mathrm{nmol} / \mathrm{L})$ and insufficiency is defined when the level is $31-20 \mathrm{ng} / \mathrm{ml}$, for the general population [5, 13]. The radioimmunoassay and competitive protein binding assays for $25(\mathrm{OH}) \mathrm{D}$ are useful in detecting vitamin $\mathrm{D}$ deficiency.

\section{Objectives}

\section{General Objective:}

1. To assess the concentrations of 25-Hydroxy Vitamin D in chronic liver disease patient.

\section{Specific Objectives:}

1. To assess $25(\mathrm{OH}) \mathrm{D}$ in relation to etiology of cirrhosis.

2. To study the relationship of level of $25(\mathrm{OH}) \mathrm{D}$ with different stage of cirrhosis according to Child-Pugh score. 


\section{Material and Methods}

This cross sectional study was carried out in the Department of Gastroenterology, Bangabandhu Sheikh Mujib Medical University, Dhaka during the period of April 2015 to March 2016. 85 patients attending the Gastroenterology Department who fulfill the inclusion criteria with cirrhosis of liver were initially be enrolled for the study. Their clinical history, examination and initial investigation report were noted in the standard data sheet. After explaining the study objective, informed consent was taken. The diagnosis of liver cirrhosis was made by combination of clinical features, blood profile and transabdominal ultrasound. Endoscopy of the upper GIT was done to see the presence of oesophageal or gastric varices which is a sign of increase portal pressure. Transabdominal ultrasound demonstrated a shrunken liver with increase echogenicity, with or without splenomegally and presence or absence of ascites. Stages of liver disease were assessed by Child-Pugh scoring system. Level of $25(\mathrm{OH}) \mathrm{D}$ was measured from blood with the permission of the Department of Bio-chemistry. Data was collected using a structered data sheet.

\section{Inclusion criteria:}

1. Patients with age greater or equal to 18 years.

2. Patients with liver cirrhosis evidence by clinical, biochemical \& ultrasonography of hepatobiliary system.

3. Patients given informed consent.

\section{Exclusion criteria:}

1. Patients with hepatocellular carcinoma.

2. Patients with evidence of ongoing pregnancy.

3. Patients with severe life threatening infection.

4. Patients who have Deformity or fracture in any part of body.

5. Female patients on hormonal contraception or in postmenopausal periods.

6. Patients who had any secondary cause associated with osteoporosis or affect BMD

7. Patients with chronic kidney disease, diabetes mellitus, history of endocrinal disease, metastatic bone disease or other malignancies.

8. Patients receiving vitamin D or calcium supplements, hormone replacement therapy, corticosteroids or any drug known to affect bone density.

\section{Operational Definition:}

Cirrhosis of Liver: Cirrhosis is a diffuse process characterized by replacement of normal liver tissue by fibrosis and regenerative nodule formation [1]. The development of cirrhosis is usually an irreversible process. The term cirrhosis is a histologic diagnosis and has its own unique constellation of clinical manifestations such that a clinical diagnosis of cirrhosis can be made with confidence most of the time. The diagnosis of cirrhosis in clinical practice is based on risk factors, history and clinical findings, biochemical tests, imaging, endoscopic and histologic findings. The diagnosis of cirrhosis is not based on a single clinical parameter but a combination of above parameters and the identification and interpretation of these findings. The most common complication of cirrhosis of liver is ascites, hepatic encephalopathy, esophageal varices, splenomegaly, hematemesis and melaena.

Vitamin D: This is a water soluble vitamin which main function is to maintain the normal skeletal architecture and also plays an important role in cardiovascular and nervous system, cellular proliferation and differentiation. Vitamin D3 is primarily acquired through the photochemical conversion of 7- dehydrocholesterol to provitamin D3 in the skin. Vitamin D2 differs in that it is incorporated into micelle then further amalgamated into chylomicron via enterocyte absorption and reaches the liver from the venous circulation for hydroxylation. The serum concentration of $25(\mathrm{OH}) \mathrm{D}$ is the most commonly used biomarker for vitamin D status.

Endoscopy: Upper gastrointestinal endoscopy will be done using a standard forward viewing endoscope. In order to prevent contamination from another patient, after each procedure endoscope and biopsy forceps will be disinfected using glutaraldehyde 2\% (CIDEX) solution. Instruments will be immersed in solution and kept for 15 minutes. Side channels will also be rinsed.

Data Collect Ion Method: Prior to data collection both verbal and written consent was taken from the respondents. Data $\wedge_{\text {recollected using a }}$ preformed data collection sheet (questionnaire). Base line information was collected from the patient after exploration of different complaints. All information regarding clinical features were recorded in a data collection sheet. S. 25-hydroxy vitamin D wow done in the Department of Bio-chemistry, Bangabandhu Sheikh Mujib Medical University Dhaka Bangladesh.

Data processing and analysis: After collection of data, all data will be checked and cleaned. After cleaning, the data will be entered into computer and statistical analysis of the results being obtained by using windows based computer software devised with Statistical Packages for Social Sciences. Numerical variables will be expressed as mean and standard deviation, whereas categorical variables are count with percentage. Continuous variables will be compared using Student's t test; categorical variables will be analyzed by Chi-square test. A p-value $<0.05$ will be considered as statistically significant. Association of serum vitamin $25(\mathrm{OH}) \mathrm{D}$ with etiology and severity will be assessed by Chisquare test. The correlation between the serum twenty five hydroxy cholecalciferol and other parameters will be evaluated by Pearson's correlation test.

Liver failure and the Child-Pugh classification: The final stage of chronic inflammation in the liver is cirrhosis. Liver cirrhosis gives rise to portal hypertension and complications such as bleeding esophageal varices, ascites and encephalopathy. Hepato-cellular failure results in hyperbilirubinemia, hypoalbuminemia and prolonged prothrombin time. The Child-Pugh classification is a scoring system used to assess the prognosis of cirrhosis.

\begin{tabular}{|c|c|c|c|}
\hline \multirow{2}{*}{ Assessment criteria } & \multicolumn{2}{|c|}{ Points scored for abnormality } \\
\cline { 2 - 4 } & $\mathbf{1}$ & $\mathbf{2}$ & Mild \\
\hline Encephalopathy grade & None & Mild & Marked \\
\hline Ascites & None & $34-50$ & $>50$ \\
\hline Bilirubin $(\mu \mathrm{mol} / \mathrm{L})$ & $<34$ & $28-35$ & $>6$ \\
\hline Albumin $(\mathrm{g} / \mathrm{L})$ & $>35$ & $4-6$ & $>2.4$ \\
\hline $\begin{array}{c}\text { Prothrombin Time } \\
\text { (seconds prolonged) } \\
\text { Or INR }\end{array}$ & $<4$ & $1.7-2.4$ & \\
\hline Individual scores should be added. & $<1.7$ & \\
\hline
\end{tabular}


7-9 = Child's B

$>9=$ Child's C

\section{Table 1. Child Pugh Score (Sherlock \& Dooley, 2011) [1]}

Although it was originally used to predict mortality during surgery, it is now used to determine the prognosis, as well as the required strength of several factors: albumin, ascites, total bilirubin, prothrombin time, and treatment and the necessity of liver transplantation. Scoring is based upon encephalopathy.

\begin{tabular}{|c|c|c|c|c|}
\hline & \multicolumn{3}{|c|}{ Survival in cirrhosis (\%) } & Hepatic deaths (\%) \\
\hline Child-Pugh grade & 1 year & 5 years & 10 years & 43 \\
\hline A & 82 & 45 & 25 & 72 \\
\hline B & 62 & 20 & 7 & 85 \\
\hline C & 42 & 20 & 0 & \\
\hline
\end{tabular}

Table 2. Survival in cirrhosis (Colledge et al. 2010) [18]

\section{Results and observations}

This cross sectional study was carried out in the Department of Gastroenterology, Bangabandhu Sheikh Mujib Medical University
(BSMMU), Dhaka from April 2015 to March 2016 for a period of 1 year. A total of 85 patients with chronic liver disease were included in this study. The results were as follows:

\begin{tabular}{|c|c|c|}
\hline Age (years) & Frequency & Percentage \\
\hline$\leq 40$ & 15 & 17.6 \\
\hline $41-50$ & 16 & 18.8 \\
\hline $51-60$ & 31 & 36.5 \\
\hline$>60$ & 23 & 27.1 \\
\hline Total & 85 & 100.0 \\
\hline Mean \pm SD & $53.0 \pm 10.7$ & \\
\hline Range (Min - Max) & $25-70$ & \\
\hline
\end{tabular}

Table 1. Distribution of patients with CLD according to age $(n=85)$

Table-1 Distribution of patients with CLD according to age. Maximum $36.5 \%$ patients were in age group 51-60 years followed by $23(27.1 \%)$, $16(18.8 \%)$ and $15(17.6 \%)$ in $>60,41-50$ and $\leq 40$ years age group respectively. Mean age was $53.0 \pm 10.7$ years within the range of $25-70$ years.

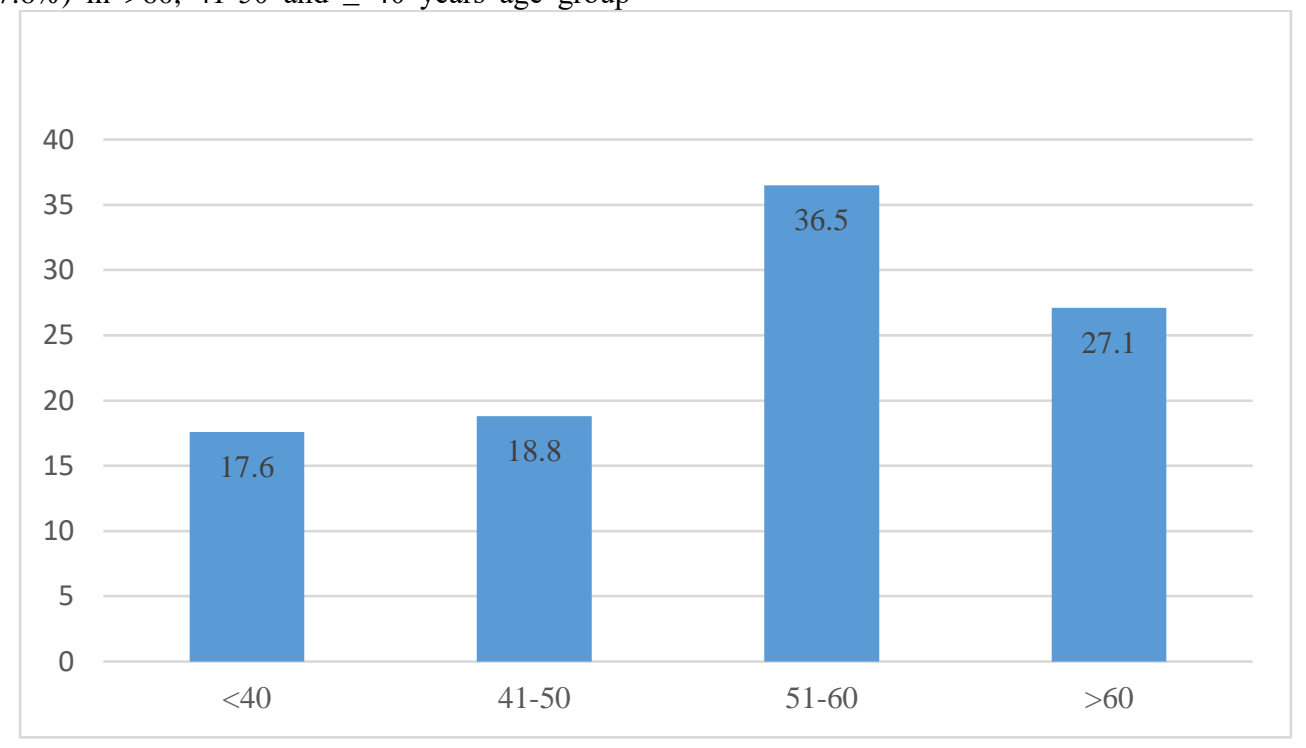

Figure-1: Bar diagram showing distribution of patients with CLD according to age.

\begin{tabular}{|c|c|c|}
\hline Gender & Frequency & Percentage \\
\hline Male & 61 & 71.8 \\
\hline Female & 24 & 28.2 \\
\hline Total & 85 & 100.0 \\
\hline
\end{tabular}

Table 2: Distribution of patients with CLD according to gender $(n=85)$

Table-2 shows distribution of patients according to gender. Male was predominant in this study. Male female ratio was $2.54: 1$ 


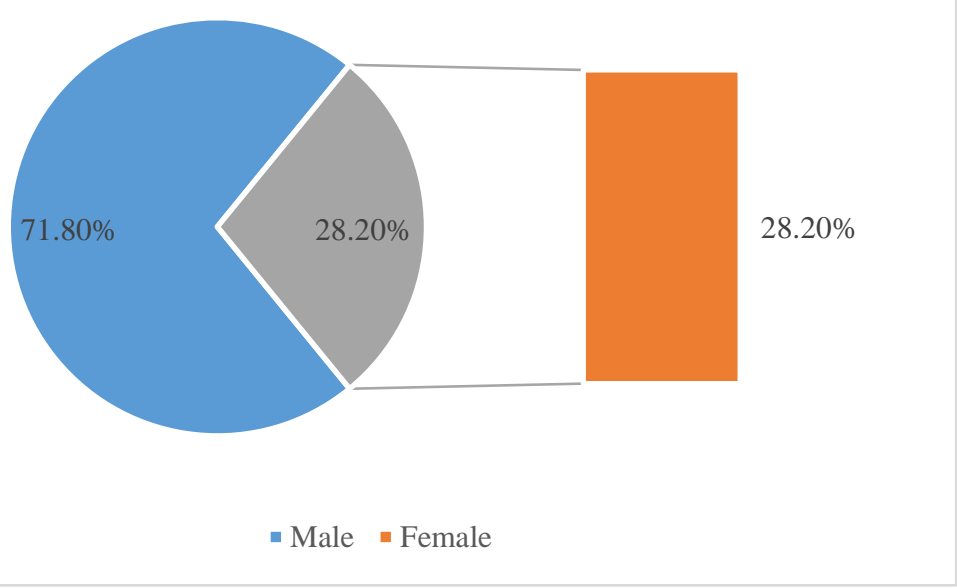

Figure-2: Shows distribution of patients according to gender.

\begin{tabular}{|c|c|c|}
\hline Presenting complains & Frequency & Percentage \\
\hline Ascites & 79 & 92.9 \\
\hline Jaundice & 61 & 71.8 \\
\hline Abdominal pain & 41 & 48.2 \\
\hline Haematemesis & 33 & 38.8 \\
\hline Melaena & 36 & 42.4 \\
\hline Anorexia & 77 & 90.6 \\
\hline Weight loss & 68 & 80.0 \\
\hline Fever & 11 & 12.9 \\
\hline Pruritus & 2 & 2.4 \\
\hline
\end{tabular}

Table 3. Presenting complain of the patients with CLD $(n=85)$

Table 3 show presenting complains of the CLD patients. More than $90.0 \%$ patients had ascites and anorexia. Eighty percent patients had weight loss and $71.8 \%$ patients had Jaundice. More than $40.0 \%$ patients had abdominal pain and melaena.

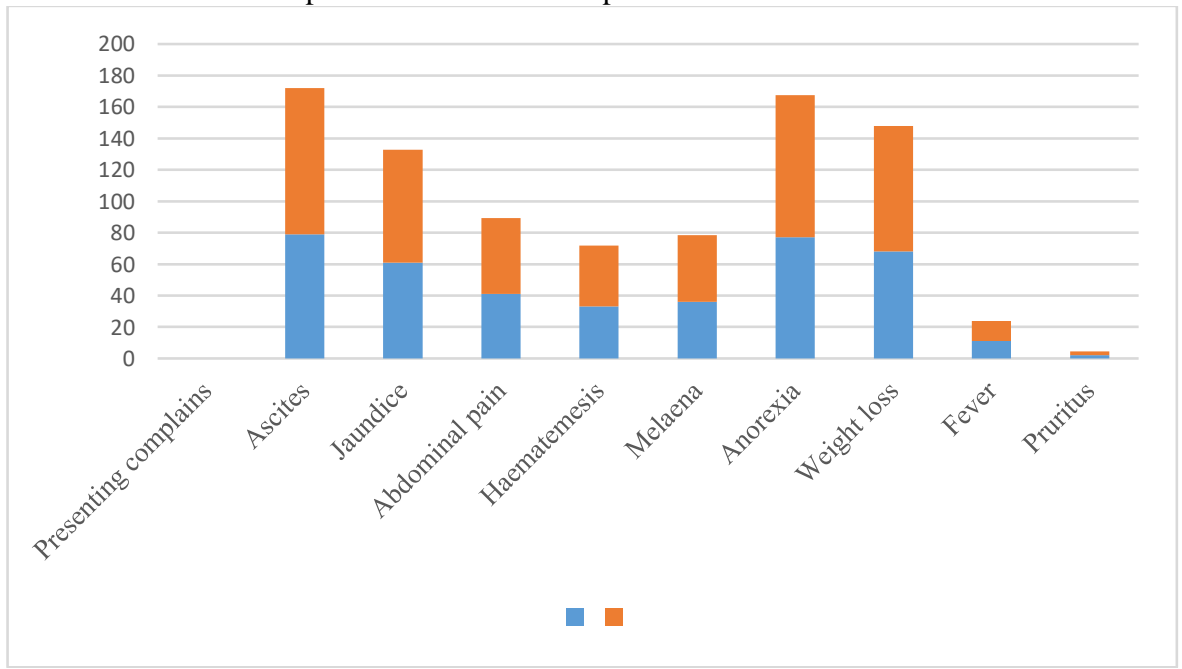

Figure-3: Presenting complain of the patients with CLD.

\begin{tabular}{|c|c|c|}
\hline History of past illness & Frequency & Percentage \\
\hline Blood transfusion & 60 & 77.9 \\
\hline Previous hospitalization & 73 & 94.8 \\
\hline Total & 85 & 100.0 \\
\hline
\end{tabular}

Table 4: History of past illness of the patients with CLD ( $n=85)$ 
Table-4 shows history of past illness. Sixty $(77.9 \%)$ patients had history of blood transfusion and $73(94.8 \%)$ patients had previous hospitalization.

\begin{tabular}{|c|c|c|}
\hline Clinical examination findings & Frequency & Percentage \\
\hline Anaemia & 83 & 97.6 \\
\hline Jaundice & 52 & 61.2 \\
\hline Lymphadenopathy & 1 & 1.2 \\
\hline Ankle oedema & 8 & 9.4 \\
\hline Leukonychia & 52 & 61.2 \\
\hline Flapping tremor & 23 & 27.1 \\
\hline Bone pain & 45 & 52.9 \\
\hline Splenomegaly & 79 & 92.9 \\
\hline Hepatomegaly & 32 & 37.6 \\
\hline Abdominal lump & 5 & 5.9 \\
\hline
\end{tabular}

Table 5: Clinical features of the patients with CLD ( $\mathrm{n}=85)$

\begin{tabular}{|c|c|c|}
\hline Laboratory test findings & Frequency & Percentage \\
\hline S. vitamin $25(\mathrm{OH}) \mathrm{D}(\mathrm{ng} / \mathrm{ml})$ & $17.03 \pm 8.41$ & $8.20-43.50$ \\
\hline $\mathrm{ESR} 1^{\text {st }} \mathrm{hr}$ & $53.90 \pm 26.91$ & $12-119$ \\
\hline $\mathrm{Hb}(\mathrm{gm} / \mathrm{dl})$ & $9.57 \pm 1.57$ & $4.10-12.00$ \\
\hline $\mathrm{WBC}($ per cumm) & $8895 \pm 2206$ & $4200-17000$ \\
\hline Haemotocrit $(\%)$ & $0.33 \pm 0.04$ & $0.30-0.40$ \\
\hline Platelet (per cumm) & $151694 \pm 79682$ & $60000-600000$ \\
\hline Serum albumin $(\mathrm{g} / \mathrm{dl})$ & $23.95 \pm 4.62$ & $17-38$ \\
\hline Serum bilirubin $(\mathrm{mg} / \mathrm{dl})$ & $2.83 \pm 1.52$ & $0.30-7.60$ \\
\hline Prothombin time & & $12-13$ \\
\hline Control & $12.01 \pm 0.11$ & $13-26$ \\
\hline Patients & $17.51 \pm 2.92$ & $0.30-1.30$ \\
\hline Serum creatinine $(\mathrm{mg} / \mathrm{dl})$ & $0.91 \pm 0.18$ & $127-144$ \\
\hline $\mathrm{Na}^{+}(\mathrm{mmol} / \mathrm{l})$ & $130.62 \pm 2.93$ & $3.20-4.80$ \\
\hline $\mathrm{K}^{+}(\mathrm{mmol} / \mathrm{l})$ & $3.93 \pm 0.41$ & \\
\hline
\end{tabular}

Table 6: Laboratory investigations of the patients with CLD $(n=85)$

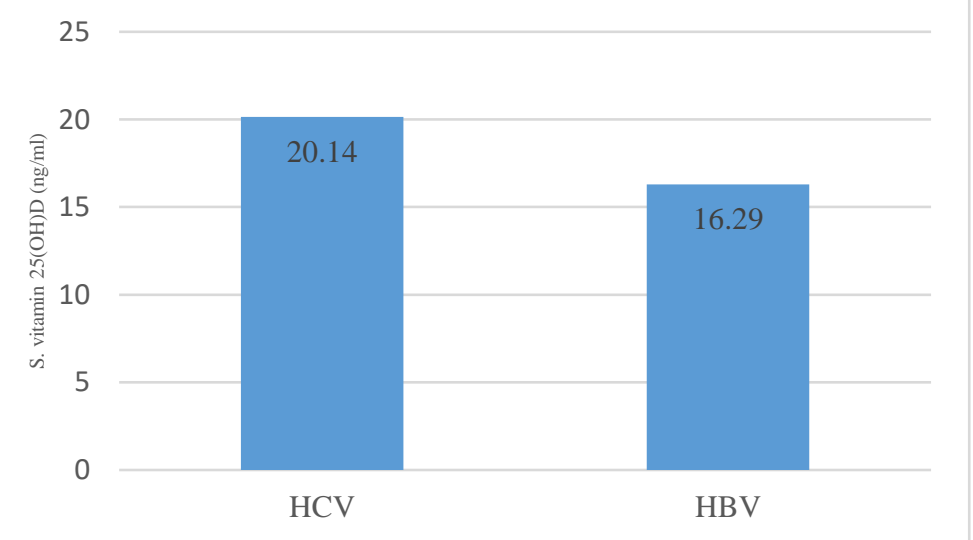

Figure-4: Bar chart showing mean S. vitamin 25(OH) D in different aetiology stages of CLD.

\begin{tabular}{|l|c|c|c|}
\hline \multicolumn{1}{|c|}{ Stage } & Mean \pm SD & Range (Min - Max) & P value \\
\hline Child-pugh A(n=25) & $27.12 \pm 5.98$ & $19.60-43.50$ & \\
\hline Child-pugh B(n=32) & $15.97 \pm 5.31$ & $10.60-27.30$ & \\
\hline Child-pugh C(n=28) & $9.57 \pm 1.15$ & $8.20-13.00$ & \\
\hline Analysis & & & \\
\hline A vs B vs C & & & $<0.001$ \\
\hline A vs B & & & $<0.001$ \\
\hline A vs C & & & $<0.001$ \\
\hline B vs C & & & $<0.001$ \\
\hline
\end{tabular}

Table 7: S. vitamin 25(OH) D in different stages of CLD $(n=85)$ 
Table 7 shows level of s. vitamin 25(OH)D in different stages of CLD. Mean s. vitamin $25(\mathrm{OH}) \mathrm{D}$ was gradually decreased as the changes of stage from lower to higher. There was statistical significant difference in s. vitamin $25(\mathrm{OH}) \mathrm{D}$ among the different stages of CLD.

\section{Discussion}

Vitamin D has pleiotropic functions. It is widely recognized to have a central role in calcium metabolism and bone mineralization. A vitamin $\mathrm{D}$ deficiency is causally related to rickets in children and osteomalacia in adults, but vitamin $\mathrm{D}$ is also physiologically important for the proper function of other organs such as skeletal muscle, heart, brain, and pancreas. Vitamin D deficiency is extremely common in chronic liver disease patients. Up to $93 \%$ of these patients have some degree of vitamin insufficiency $[6,19]$. Even patients with mild liver disease are affected, although liver cirrhosis patients more commonly suffer from severe deficiency. In this study, males were predominant. Male female ratio was 2.54:1. Males were predominant and male female ratio was 2.70:1 [20]. The male female ratio was in the range of 2.3:1 to 2.6:1 among the patients with cirrhosis and HCC [21]. All these results are similar to this study result. Male female ratio of patients with CLD in Malayasia was 4.4:1 [22]. Maximum 36.5\% patients were in age group 51-60 years followed by $23(27.1 \%), 16(18.8 \%)$ and $15(17.6 \%)$ in $>60,41-50$ and $<40$ years age group respectively. Mean age was $53.0 \pm 10.7$ years within the range of 25-70 years. Mean age of patients with CLD in Malayasia was 52 years which is almost similar to this study [22]. Regarding presenting complains, more than $90.0 \%$ patients had ascites and anorexia. Eighty percent patients had weight loss and $71.8 \%$ patients had Jaundice. Almost fifty patients had abdominal pain $(48.2 \%)$ and melaena $(42.4 \%)$. Haematemesis was present in $38.8 \%$ patients and fever was present in $12.9 \%$ patients. Dhole et al. [23], found jaundice in (73.0\%), abdominal distension in $(51.0 \%)$ and Ascites in (41.8\%) Patients [23]. Ascites is more in this study compare to Dhole et al. [23], but other presenting complains are similar to Dhole et al. Regarding clinical examination findings of the CLD patients, most of the patients had anaemia (97.6\%) and Splenomegaly (92.9\%). More than $50.0 \%$ patients had jaundice $(61.2 \%)$, Leukonychia (61.2\%) and bone pain (52.9\%). Hepatomegaly, flapping tremor, ankle oedema, abdominal lump and lymphadenopathy were present in $37.6 \%, 27.1 \%, 9.4 \%, 5.9 \%$ and $1.2 \%$ patients. Hepatomegaly was seen in $63 \%$ patients, splenomegaly was seen in $60 \%$ patients and anaemia in $56.0 \%$ patients [23]. In this study, anaemia and splenomegaly is more comparing Dhole et al. hepatomegaly was less comparing Dhole et al.[23]. In this study mean s. vitamin 25(OH) D was $17.03 \pm 8.41$. Putz-Bankuti et al. [24], reveled mean 25(OH)D was $16.0 \pm$ $9.2 \mathrm{ng} / \mathrm{ml}$ and Lange et al. (2011) revealed mean 25(OH)D was $17 \mathrm{ng} / \mathrm{ml}$ (range: 3-80) [14]. Mean s. vitamin 25(OH) D was $16.29 \pm 7.96$ in 69 HBV patients and $20.14 \pm 9.76$ in $16 \mathrm{HCV}$ patients. Mean s. vitamin $25(\mathrm{OH}) \mathrm{D}$ found in this study is almost similar to the above studies. Mean s. vitamin $25(\mathrm{OH}) \mathrm{D}$ was $7.65 \pm 4.19$ in $\mathrm{HBV}$ patients which is less comparing these study [15]. Chronic hepatitis $\mathrm{C}$ virus (HCV) infection is one of the main causes of chronic liver disease; it is estimated to affect 130 to 150 million people worldwide, a significant number of whom also develop cirrhosis and hepatic cancer [16]. A high percentage of these patients ( $46 \%$ to $92 \%$ ) have low vitamin D levels, and more than $25 \%$ suffer from severe deficiency [7]. It has been hypothesized that the high incidence of vitamin D deficiency in these patients may be caused by HCV's effect on direct or indirect 25-hydroxylation through cytokine induction or oxidativc stress [28], and that the virus may suppress $25(\mathrm{OH}) \mathrm{D}$ levels due to a disruption in lipid metabolism; as shown a recent study where HCV decreases the production of 7-dehydrocholesterol, the endogenous precursor of vitamin D [27]. In this study, $28.2 \%$ patients were in child Pugh class A, 36.4\% in child Pugh class B and $32.9 \%$ in child Pugh class C group. Majority of CLD patients $63.0 \%$ fall in child Pugh class A group, followed by $32.0 \%$ fall in child Pugh class B \& 5.0\% fall in child Pugh class C [20]. Child Pugh class B is similar in both studies but child pugh class $\mathrm{A}$ in higher and child pugh class $\mathrm{C}$ is lower in this study comparing [20]. Mean s. vitamin 25(OH) D were 27.12 \pm 6.11 , $15.97 \pm 5.40$ and $9.57 \pm 1.15$ in Child-pugh A, Child-pugh B and Childpugh $\mathrm{C}$ stages respectively. Mean s. vitamin 25(OH) D was gradually decreased as the changes of stage from lower to higher. There were significant differences in s. vitamin 25(OH)D among Child Pugh scores with the highest levels in Child A and the lowest levels in Child $\mathrm{C}$ patients (Finkelmeier, 2015). The studies by Crawford et al. [26], Fisher et al. [19], Chen et al. [25] and Putz-Bankuti et al. [24] show that patients with severe cirrhosis (Child-Pugh class $C$ ) have approximately half the amount of serum 25-hydroxyvitamin D concentrations compared with patients with less severe cirrhosis (Child-Pugh class A).

\section{Conclusion}

In this study, 85 patients were enrolled and the mean S. 25(OH)D was 17.03 which was in the lower limit. The patient was also categorized according to severity with Child-Pugh classification and showed the level of vitamin D is inversely related to the severity of the disease.

\section{Limitations and Recommendation}

1. No control.

2. Sample size is small.

3. Study was carried out in BSMMU and it is not the actual reflection of total population.

4. A multicenter, population based with control and having a larger sample size study should be done. So that, it can be properly evaluated and will be more correct.

\section{References}

1. Sherlock S. and Dooley J. (11th edn) (2002). 'Diseases of the Liver and Biliary System', Blackwell Scientific Publications, Oxford.

2. AGA Clinical Practice Committee. (2003), 'AGA technical review on osteoporosis in hepatic disorders'. Gasfwwrttero/ogy, vol. 125, pp. 941-66.

3. Pugh RNH, Dawson JL, and William R. (1977). Transection of the oesophagus for bleeding oesophageal varices', British Journal of Surgery, vol. 60, pp. 646-49.

4. Compston JE. (1986) 'Hepatic osteodystrophy: Vitamin D metabolism in patients with liver disease' Gut, vol. 27, pp. 107390.

5. Hollick MF. (2005). 'Variations in 25-hydroxyvitamin I) assay results'. Journal of Clinical Endocrynology and Metabolism, vol. 90(5). pp. 210-15.

6. Aneh J. Narra S. and Nair S. (2010). 'Prevalence of vitamin D deficiency in chronic liver disease', Djgextive Disease Science, vol. 55, pp. 2624-28.

7. Petta S, Camma C Scazzone C, Tripodo C, Di Marco V, Bono A, Cabibi D, Licata G, Porcasi R, Marchesini G and Craxi A. (2010), Low vitamin $\mathrm{D}$ serum level is related to severe fibrosis and $\left.\bullet{ }^{\prime}\right)$ responsiveness to interferon-based therapy in genotype 1 chronic hepatitis $\mathrm{C}^{\prime}, \mathrm{H}^{\wedge}$ ology. Vo1-51, pp. 1158-67.

8. Rose J, Compston JE, and Evans W. (1991). 'Osteoporosis associated with chronic liver disease', European Journal of Gastroenterology and Hepatology, vol. 3, pp. 63-69.

9. Matsumura T, Kato T. Tasaka-Fujita M, Murayama A, Masaki T, and Wakita T. (2006). '25hydroxyvitamin D inhibits hepatitis C virus replication and production of the infectious viruses', Hepatology, vol. 54, pp. 54-67.

10. Diamond TH, Stiel D, Lunzcr M, McDowall D, Eckstein RP, and Posen S. (1989). 'Hepatic osteodyslrophy. Static and dynamic bone histomorphometry and bone Gla-protein in 80 patients with chronic liver disease' Gastroenterology vol. 96, pp.213-21. 
11. Diamond TH, Stiel D, Lunzer M, Wilkinson M, and Roche J. (1990). 'Osteoporosis and skeletal fractures in chronic liver disease', Gut, vol. 31, pp. 82-87.

12. Monegal A, Navasa M, and Ouanabcns. (1997), 'Osteoporosis and bone mineral metabolism disorders in cinhotic patients referred for orthotopic liver transplantation', Calcified Tissue International, vol. 60, pp. 148-54.

13. Kilson MT, Sarrazin C, Toniutto P, Eslick DG, and Roberts SK. (2012). 'The importance of vitamin D status in chronic liver disease'. Journal of Hepatology, vol. 57, pp. 897-09.

14. Farnik H, Bojunga J, Berger A, Allwinn R, Waidmann O, Kronenberger B, Keppler TO, Zeuzem S, Sarrazin C, and Lange CM. (2013). 'Low vitamin D serum concentration is associated with high levels of hepatitis B virus replication in chronically infected patients' Hepatology, vol. 58, pp. 1270-76.

15. Demir C and Demir M. (2013). 'Vitamin D levels in patients with chronic hepatitis B virus infection and naturally immunized individuals' Internal Medicine Inside, vol. 1(1), pp. 2-6.

16. WHO (2014) Fact sheet $\mathrm{N}^{\circ} 164$. [Updated 2014 April].

17. Stokes CS, Volmer DA, Grunhage F, and Lammert F. (2013). 'Vitamin D in chronic liver disease, Liver International, vol. 33, pp. 338-52.

18. Carey J, Halan V, Krcmcrs, and Hay WK. (2003). 'Osleopenia and osteoporosis in patients with end-stage liver disease caused by hepatitis $\mathrm{C}$ and alcoholic liver disease: Not just a cholestatic problem', Liver Transportation, vol. 9(11), pp. ] 166-73

19. Fisher L, and Fisher A. (2007). 'Vitamin D and parathyroid hormone in outpatients with noncholestatic chronic liver disease', Clinical Gastroenterology and Hepatology, vol. 5, pp. 513-20.

20. Hossain SF, Islam QT, Siddiqui MR, Hossain A, Jahan N, Rahman N, and Iqbal MJ. (201 1). 'A study of hypoalbuminemia in chronic liver disease and its correlation with development of csophageal variccs' Bangladesh Journal of Medicine, vol. 22, pp. 17-20.

21. Shimizu I, Inoue H, Yano M, Shinomiya H, Wada S andTsuji Y. (2001). 'Estrogen receptor levels and lipid peroxidation in hepatocellular carcinoma with hepatitis $\mathrm{C}$ virus infection', Liver, (2001). Vol. 21, pp. 342-49.

22. Kudva MV, and Zawawi MM. (1990). 'Chronic liver disease in Kualalumpur, Malaysia: A c'inical study'. Singapore Medicine Journal, vol. 31, pp. 368-73.

23. https://pubmed.ncbi.nlm.nih.gov/26393179/Dhole\%20et\%20al,K her\%20AS, Ghildiyal\%20RG,Tambse\%20MP:\%20Chronic\%20L iver\%20Diseases\%20in\%20Children:\%20Clinical\%20Profile\%2 0and\%20Histology.\%20http:/europepmc.org/article/med/263931 79.

24. Putz-Bankuti C, Pilz S, Stojakovic T, Scharnagl H, Pieber TR, Trauner M, Obermeyer-Pietsch B, and Stauber RE. (2012), 'Association of 25-hydroxyvitamin D levels with liver dysfunction and mortality in chronic liver disease' Liver international, vol. 32(5), pp. 845-51.

25. Chen CC, Wang SS, Jcng FS, and Lee SD. (1996). 'Metabolic bone disease of liver cirrhosis: Is it parallel to the clinical severity of cirrhosis?' Journal of Gastroenterology and Hepatology, vol. 11, pp.417-21.

26. Crawford BA, Labio ED, Strasser SI, and McCaughan GW. (2006) 'Vitamin D replacement for cirrhosis- related bone disease', Nature clinical practice, Gastroenterology and Hepatology, vol. 3(12), pp. 689-99.

27. Clark PJ, Thompson AJ, Vock DM, Kratz LE, Tolun AA, Muir AJ, McHutchison JG, Subramanian M, Millington DM, Kelley RI, and Patel K. (2012), 'Hepatitis C virus selectively perturbs the distal cholesterol synthesis pathway in a genotype-specific manner.' Hepatology 2012.

28. Bellecave P, Sarasin-Filipowic/. M. Don/e O, Kennel A, Gouuenoirc J, Mcylan E, Terracciano L, Tschopp J, Sarrazin C, Berg T, Moradpour D, and 1-leim MH. (2010), 'Cleavage of mitochondrial antiviral signaling protein in the liver of patients with chronic hepatitis $\mathrm{C}$ correlates with a reduced activation of the endogenous interferon system, Hepatology, vol. 51, pp.1127-36.

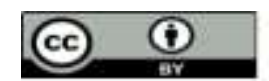

This work is licensed under Creative Commons Attribution 4.0 License
Ready to submit your research? Choose Auctores and benefit from:

* fast, convenient online submission

* rigorous peer review by experienced research in your field

* rapid publication on acceptance

* authors retain copyrights

* unique DOI for all articles

* immediate, unrestricted online access

At Auctores, research is always in progress.

Learn more www.auctoresonline.org/journals/gastroenterologypancreatology-and-hepatobilary-disorders 